\title{
Some Numerical Methods for Temperature and Mass Transfer Simulation on the Dehydration of Herbs
}

\author{
Md. Rajibul Islam, Member, IACSIT and Norma Alias
}

\begin{abstract}
Advances in herbs based products preservation and technologies are very significant in order to reduce post-harvest losses. The dynamic mathematical model of concurrent heat and moisture transfer are being established for the simulation of temperature and moisture distributions inside the herbs material during dehydration potential of herbs in a slab-shaped solid. Mathematical modeling presents the exchange of heat and mass transfer between material and drying air. Finite-difference method (FDM) based on Crank-Nicolson was used to discretise a parabolic type partial differential equations (PDE). The key purpose of this study is to illustrate the simulation of tropical herbs' dehydration through some numerical methods such as Jacobi, Gauss-Seidel and Red-Black Gauss-Seidel. This study focuses on the implementation of sequential algorithms on the simulation. 3D geometric visualization by COMSOL Multiphysics and graphical numerical results of FDM approximation in mass and heat transfer demonstrate the results of this study. The contribution of this study is a flourishing and modified mathematical simulation in representing the concrete process of dehydration in herbs product based industry. Most thermal and moisture models are empirical rather than theoretical. Therefore, the novelty of this paper is the best sources of thermal and moisture data for the commercial tropical herbs dehydration derived from the mathematical model in order to avoid high prototype costs and to improve inaccurate conditions and process parameters with the advancement of dryer technologies. The computational platform is based on Intel ${ }^{\circledR}$ Core $^{\mathrm{TM}} 2 \mathrm{Quad}$ processors with MATLAB software. The performance analyses of Numerical methods are presented in terms of execution time, computational complexity, number of iterations, errors, accuracy, and convergence rate.
\end{abstract}

Index Terms - Parabolic Equation, dehydration, tropical herbs, iterative methods, heat and mass transfer.

\section{INTRODUCTION}

The potentiality of Herbal sector has been identified as the largest contributor to the growth of the Malaysian economy. Malaysian herbs are of superior quality and suitable for the

Manuscript received November 12, 2009

This work was supported in part by Ministry of Science, Technology and Innovation (MOSTI), Malaysia under Grant 78363.

Md. Rajibul Islam was with the Faculty of Information Science and Technology (FIST), Multimedia University, 75450 Melaka, Malaysia. He is currently working as a Research Assistant in Ibnu Sina Institute, Faculty of Science, University Technology Malaysia, 81310 UTM Skudai, Johor (Corresponding author's mobile: +60-162-489860; e-mail: md.rajibul.islam05@mmu.edu.my).

Dr. Norma Alias is with Ibnu Sina Institute, Faculty of Science, University Technology Malaysia, 81310 UTM Skudai, Johor. She is working as a Senior Lecturer as well as a Researcher in the mathematic department, UTM. (Phone: +60-755-36041; Mobile: +60-127-299094). local market. Malaysia has over 2000 plants that possess medicinal value. Demands for herbal products like Medicinal plants and herbs based products such as pegaga, kacip fatema, misai kacig (local name) for healthy, beauty and youngerness, are on the rise as consumers are becoming more health and beauty conscious. The Medicinal plants and herbs based products need to be processed to prolog their shelf life. Herbal producers therefore have to be aware of advances in Medicinal plants and herbs based products processing and post harvest technologies in order to efficiently reduce post-harvest losses. It is necessary to dry the herbs based products to a certain level after harvest. Drying removes the water or moisture from the herbs based products so that bacteria, yeast and molds cannot grow up and spoil the herbs products especially for the purpose of storage years and years. It is also used to reduce the cost or difficulty of packaging, handling and transportation. Simulation results and information of drying kinetics of herbs products such as drying rates, time-temperature-moisture content distributions, as well as theoretical and empirical approaches to moisture movement, is very essential for the prevention of quality degradation and for the achievement of fast and effective drying. A greater part of drying R\&D efforts is reliable nowadays to the agricultural segments [10]. Nowadays, the use of technology has been a must in almost all of industries in Malaysia to improve their service and productivity in order to fulfill the customers' demands. Drying processes are widely used in herbs preservation but a scientific approach has not so widely been applied, so rather empiric rules are often used to set up industrial production, particularly in small-medium firms.

The core point of herbs drying process is water removal up to particular moisture content to prevent herbs from microbial spoilage and deterioration reactions and to increase the product shelf life [5]. It is a complex procedure relating concurrent heat and mass transfer phenomena. The formulation of sufficient mathematical models to optimize the process-leading can be enhanced product quality and a reduction in process cost. Improving speed and product quality requires a reduction in decision latency which decreases the amount time it takes people to share information and make critical decision, all along a value chain of suppliers, partners and customers. Selecting an appropriate drying model to evaluate the drying distribution is very important to get best prediction of drying kinetics. In the dehydration process, it is important to know the temperature and moisture dstribution in the material and its 
change during dehydrating; the presented mathematical model is able to predict this. The governing differential equations describing moisture content and temperature distribution were solved numerically. The mathematical model using PDE will be helpful to estimate the drying rate at any moisture condition of the material and to estimate drying time for particular task during dehydration of herbs based products. Computer program was developed to solve the set of finite difference equations.

Computer simulation is a powerful tool for achieving measurement of changes in temperature and moisture during dehydration process. Simulation results and information of drying kinetics of herbs material such as time, temperature, moisture content distributions, as well as theoretical approaches to moisture movement, is very essential for the prevention of quality degradation and for the achievement of fast and effective drying. Such information will be very useful to optimize production processes of herbs dried. The increasing development of computer program had a great impact on the quality evaluation of agricultural products. Invention of the computer also influenced the field of numerical analysis, since nowadays longer and more complicated calculations could be done. However, the objectives of this study are: (i) To derive simulation of moisture and temperature versus time in producing dehydration of herbs products based on convection-diffusion model using partial difference equation (PDE) and (ii) To provide some methods for solving the parabolic PDE equations; and to analysis performance of each method presented in terms of temperature and moisture content values.

The majority of thermal property models are experimental rather than hypothetical; specifically most of them are based on statistical curve fitting relatively than hypothetical derivations concerning mass and heat transfer study. Water is treated as a single, homogeneous part of the herbs product in modeling. It could be disagreed that the thermal properties of water in the herbs depend on how it is configured or "bound" within the product [6]. In fact of integration technologies in herbs production, it is necessary to simulate more often in order to control prototype costs and to simulate better in order to get process parameters with the needed accuracy. Hence, some modeling studies are essential on heat and mass transfer features to enhance drying conditions and process parameters [2]. The high contribution of this paper is successful modified the mathematical simulation in representing the actual process of dehydration in commercial herbs industry in terms of heat and mass transfer inside tropical herbs material.

Accuracy greater than $2-5 \%$ is rarely required for most engineering heat transfer calculations performed in commercial herbs dehydration [6]. This happens because of the errors during wrongly considered boundary conditions such as the temperature and velocity of air would overshadow errors caused by imprecise thermal properties. One way to get the sources of thermal property data are prediction and simulation equations based on temperature and physical structure (density, size and configuration of void spaces). The originality of this study is to present greatest sources of thermal and moisture property data for commercial tropical herbs dehydration through heat and mass transfer equations based on temperature and moisture aspects to evade high prototype costs. It also can improve drying conditions and process parameters as well as evolution of dryer technologies with needed accuracy.

\section{MAthematical Simulation MOdELING}

Drying kinetics can be modeled mathematically based on Fick's law of diffusion. The simulation of various product drying systems involves solving a set of heat and mass transfer equations. Maroulis et al. [9] described transport phenomena as follows:

\section{i. Heat transfer :}

Convective heat (energy) transfer from the air to the food's surface (external heat transfer)

Conductive heat transfer within the food (internal heat transfer) and air,

\section{ii. Moisture transfer :}

Moisture transport within the food towards its external surface (internal mass transfer)

The first drying process is heat transfer to the product from the heating source and the second is mass transfer from the interior of the material to its surface and from the surface to the surrounding air. The heat and mass transfer equations are presented in the model below are governed by the following PDE. In this model, the moisture transport arises by diffusion in only one direction; from the interior of the products to the air-sample interface, and evaporation takes place at the interface. Shrinkage of herbs products during drying is an noticeable physical incident, which occurs concurrently with moisture diffusion. These models had been presented by $\mathrm{Md}$ Azharul Karim and Hawlader [7]. To simplify the model, Md Zaharul Karim and Hawlader [8] were made the following assumptions:

i. Moisture movement and heat transfer are one-dimensional.

No chemical reaction performs during drying, to be precise material, air and moistures' thermal and chemical properties are constant within the range of temperatures considered.

ii. The material becomes shrinkage after drying progresses.

iii.Uniform distribution of air through the dryer.

Mass transfer equation can be written as:

$$
\frac{\partial M}{\partial t}+u \frac{\partial M}{\partial x}=D \frac{\partial^{2} M}{\partial x^{2}} \text {, }
$$

and similarly, the heat transfer equation can be written as:

$$
\frac{\partial T}{\partial t}+u \frac{\partial T}{\partial x}=\alpha \frac{\partial^{2} T}{\partial x^{2}}
$$

With the following initial (IC) and boundary conditions (BC) of equation (1) and (2) are given below:

IC: $\left.M\right|_{x=0}=M_{0},\left.T\right|_{x=0}=T_{0}$

BC: At $x=0 ;\left.\frac{\partial M}{\partial x}\right|_{x=0}=0$ and at $x=b$, moisture balance is

$-\left.D_{e f f} \frac{\partial M}{\partial x}\right|_{x=b}+\left.u M\right|_{x=b}=\left.h_{m}\left(M-M_{e}\right)\right|_{x=b}$ 


$$
\begin{aligned}
& \text { and }\left.\frac{\partial T}{\partial x}\right|_{x=0}=0 \text { and at } x=b, \text { heat balance is } \\
& \left.\left(k \frac{\partial T}{\partial x}-\rho_{c} p T\right)\right|_{x=b}=\left.h\left(T_{a}-T\right)\right|_{x=b}-\left.h_{m} \rho\left(M-M_{e}\right) h f g\right|_{x=b}
\end{aligned}
$$

\begin{tabular}{ll}
\multicolumn{2}{l}{ TABLE 1: PARAMETERS OF MASS AND HEAT TRANSFER EQUATION } \\
\hline Notation & \\
\hline$b$ & half thickness of drying specimen $(\mathrm{m})$ \\
$c_{p}$ & specific heat $(\mathrm{J} / \mathrm{kgK})$ \\
$D$ & diffusion coefficient $(\mathrm{m} 2 / \mathrm{s})$ \\
$h$ & convective heat transfer coefficient $(\mathrm{W} / \mathrm{m} 2 \mathrm{~K})$ \\
$h f g$ & enthalpy of evaporation $(\mathrm{J} / \mathrm{kg})$ \\
$h m$ & mass transfer coefficient $(\mathrm{m} / \mathrm{s})$ \\
$k$ & thermal conductivity $(\mathrm{W} / \mathrm{m} \mathrm{K})$ \\
$L$ & thickness of the drying specimen $(\mathrm{m})$ \\
$M$ & moisture content of specimen $(\mathrm{g} / \mathrm{g}$ dry $)$ \\
$t$ & time (s) \\
$T$ & temperature $\left({ }^{\circ} \mathrm{C}\right)$ \\
$u$ & shrinkage velocity $(\mathrm{m} / \mathrm{s})$ \\
$x$ & distance from the centre of the drying specimen $(\mathrm{m})$ \\
\hline Subscript & \\
\hline$S$ & initial, reference \\
0 & air \\
$a$ & equilibrium \\
$e$ & effective \\
$e f f$ & material (herbs sample) \\
$m$ & mol \\
\hline &
\end{tabular}

\section{DISCRETIZATION}

Discretization involved with the transformation of continuous differential equations into discrete difference equations is appropriate for numerical computing. A discrete form can be found by using FDM. Betta G., et al [4], Amendola and Queiroz [3], Tabrizi and Hamdullahpur [12], Ahmet Kaya et. al. [1], Md Zaharul Karim and Hawlader [7][8] and Queiroz and Nebra [11] were solved their dehydration model using FDM.

In this study, Crank-Nicolson scheme was used to descritise the diffusion and convection terms for the equation (1) and (2). Subsequently, some iterative methods were applied to solve both the equations. In order to simulate the mass and heat transfer numerically, the Crank-Nicolson FDM method was applied to discretise the equation (1) and (2). Wang and Brennan [13], Md Zaharul Karim and Hawlader [8], Ahmet Kaya et al. [1] utilized implicit Crank-Nicolson scheme with the numerical procedure in their experiments. The drying material is considered as a thin slab of thickness, $L(2 b)$ at a uniform initial temperature, $\mathrm{T}_{0}$ and moisture content, $\mathrm{M}_{0}$ according to $\mathrm{Md}$ Zaharul Karim \& Hawlader [8].

For this method, the simulated material (total thickness, $L$ ) are sliced up into $N i$ samples and the times (total duration $T$ ) are split into $N j$ samples: $h=\Delta x=b / N i$ and $k=\Delta t=T / N j$. According to Crank-Nicolson schemes (where $i$, represents position and $j$, represents time), the derivative of diffusion term for the equation (1) and (2) can be written as;

$$
\begin{aligned}
& D \frac{\partial^{2} M}{\partial x^{2}}=\frac{D}{2}\left[\frac{M_{i+1, j+1}-2 M_{i, j+1}+M_{i-1, j+1}}{(\Delta x)^{2}}+\frac{M_{i+1, j}-2 M_{i, j}+M_{i-1, j}}{(\Delta x)^{2}}\right] \\
& \alpha \frac{\partial^{2} T}{\partial x^{2}}=\frac{\alpha}{2}\left[\frac{T_{i+1, j+1}-2 T_{i, j+1}+T_{i-1, j+1}}{(\Delta x)^{2}}+\frac{T_{i+1, j}-2 T_{i, j}+T_{i-1, j}}{(\Delta x)^{2}}\right]
\end{aligned}
$$

And the derivations of convection term for both equations are;

$$
\begin{aligned}
& u \frac{\partial M}{\partial x}=\frac{u}{2}\left[\frac{M_{i+1, j+1}-M_{i-1, j+1}}{2(\Delta x)}+\frac{M_{i+1, j}-M_{i-1, j}}{2(\Delta x)}\right] \\
& u \frac{\partial T}{\partial x}=\frac{u}{2}\left[\frac{T_{i+1, j+1}-T_{i-1, j+1}}{2(\Delta x)}+\frac{T_{i+1, j}-T_{i-1, j}}{2(\Delta x)}\right]
\end{aligned}
$$

The governing equations describing drying characteristics were solved numerically. Physical properties of the tropical herbs considered for the experiments, were adopted from $\mathrm{Md}$ Zaharul Karim \& Hawlader [7]. A computer program was developed by MATLAB software to solve the set of PDEs.

\section{A. Iterative Method}

Iterative methods can be performed to system as many as 100,000 variables. These large systems arise to solve the PDEs. Starting from a primary guess, iterative methods form consecutive estimates that meet to the precise solution only in the limit. A convergence condition is stated in order to make a decision while an adequately precise solution has (expectantly) been found. There are many versions of iterative schemes for solving the PDEs, we focus the implementation of some popular iterative solvers here using some sequential programming, such as Jacobi, Gauss-Seidel, and Red-Black Gauss-Seidel Methods [14]. A brief description of each method is given below.

\section{B. Jacobi Iteration Method (JB)}

The Jacobi iteration method is attributed to Carl Jacobi. Jacobi iteration is a simple and fundamental point iterative method. Jacobi method computes the value of moisture or temperature by solving for each component of $\mathrm{x}$ in terms of others by

$x_{i}^{(k+1)}=\left(b_{i}-\sum_{j \neq i} a_{i j} x_{j}^{(k)}\right) / a_{i i}, i=1,2,3, \ldots \mathrm{m}$.

\section{Gauss Seidel Iteration Method (GS)}

The Gauss Seidel method is an enhanced version of the Jacobi method developed by the Carl Friedrich Gauss and Philipp Ludwig von Seidel. The Gauss Seidel (GS) method computes the value of moisture or temperature by

$x_{i}^{(k+1)}=\left(b_{i}-\sum_{j<i} a_{i j} x_{j}^{(k+1)}-\sum_{j>i} a_{i j} x_{j}^{(k)}\right) / a_{i i}, i=1,2,3, . . \mathrm{m}$

\section{Red-Black Gauss Seidel Iteration Method (RBGS)}

The Red-Black Gauss Seidel (RBGS) method contains 2 sub domain, $\Omega^{R}$ and $\Omega^{B}$. There exists a communication between $\Omega^{R}$ and $\Omega^{B}$. The calculation of this method is shown by the equations below:

i) grid calculation at $\Omega^{R}$ : 
$x_{i}^{(k+1)}=\left(b_{i}-\sum_{j<i} a_{i j} x_{j}^{(k+1)}-\sum_{j>i} a_{i j} x_{j}^{(k)}\right) / a_{i i}$,

ii) grid calculation at $\Omega^{B}$ :

$x_{i}^{(k+1)}=\left(b_{i}-\sum_{j<i} a_{i j} x_{j}^{(k+1)}-\sum_{j>i} a_{i j} x_{j}^{(k+1)}\right) / a_{i i}$,

For every method above,

$x_{i}^{(k+1)}$ is the $i^{\text {th }}$ unknown current value in $x$ during the $k+1^{\text {th }}$ iteration, $\boldsymbol{i}=\mathbf{1}, \mathbf{2}, \ldots \mathrm{Ni}$ and $k=0,1$,

$x_{i}^{(k)}$ is the $i^{\text {th }}$ unknown in $x$ during the $k^{\text {th }}$ iteration, $i=1$, $2, \ldots N i$ and $k=0,1$,

$x_{i}^{(0)}$ is the initial value for the $i^{\text {th }}$ unknown in $x$ during the $k^{\text {th }}$ iteration, $i=1,2, \ldots N i$ and $k=0,1, \ldots$

$a_{i j}$ is the coefficient of $\mathrm{A}$ in the $i^{\text {th }}$ row and $j^{\text {th }}$ column

$b_{i}$ is the value $x_{i}^{(k-1)}$ and

$a_{i i} \neq 0$.

All the iterative methods were being repeated a process over and over until an approximation of the solution was reached. The stopping criterion that was used for all the methods, depended on a convergence tolerance, $\mathcal{E}$ such that $\left|x_{i}^{(k+1)}-x_{i}^{(k)}\right| \leq \varepsilon$. Equation (1) and (2) was solved for the current moisture content, $M_{i}^{(k+1)}$ and temperature, $T_{i}^{(k+1)}$ in term of $x_{i}^{(k+1)}$ shown above.

\section{Algorithm AND PROTOTYPE}

\section{A. Procedure}

Figure 1 shows the flow of calculation to simulate temperature and moisture behavior inside herbs material during dehydration process. The item count represents the number of iterations taken to fulfill the stopping criterion. Meanwhile, round is declared as number of time step in order to get new $M_{i}$ and $T_{i}$ value.

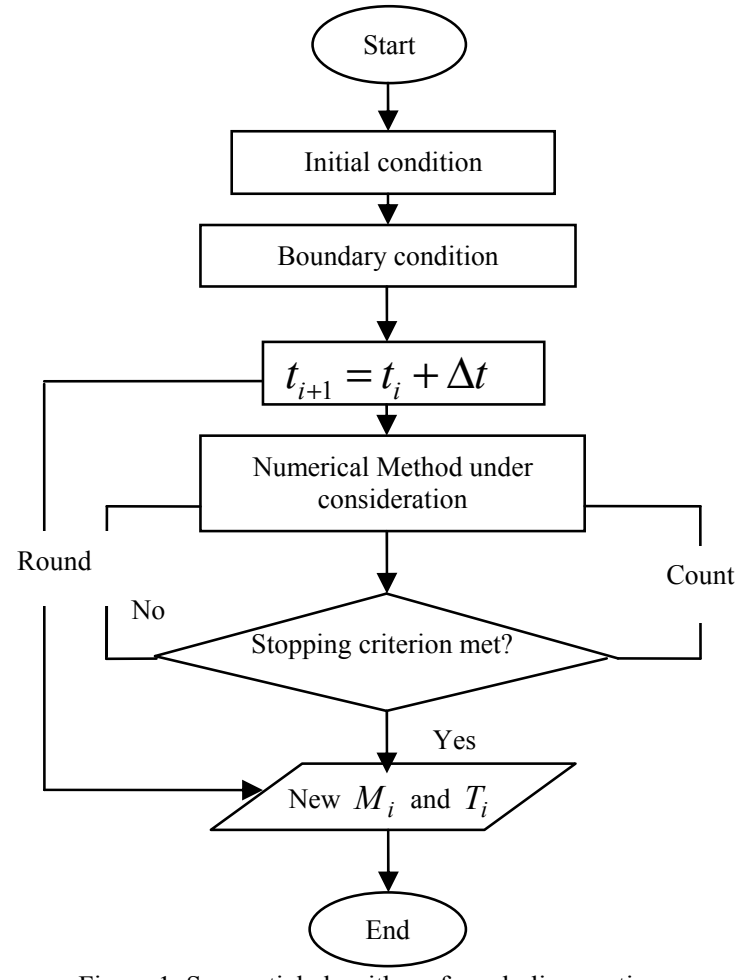

Figure 1: Sequential algorithm of parabolic equation

\section{B. MATLAB Program}

Based on algorithm above, programming in MATLAB was developed to solve the equations. Figure 2 shows a part of the program.

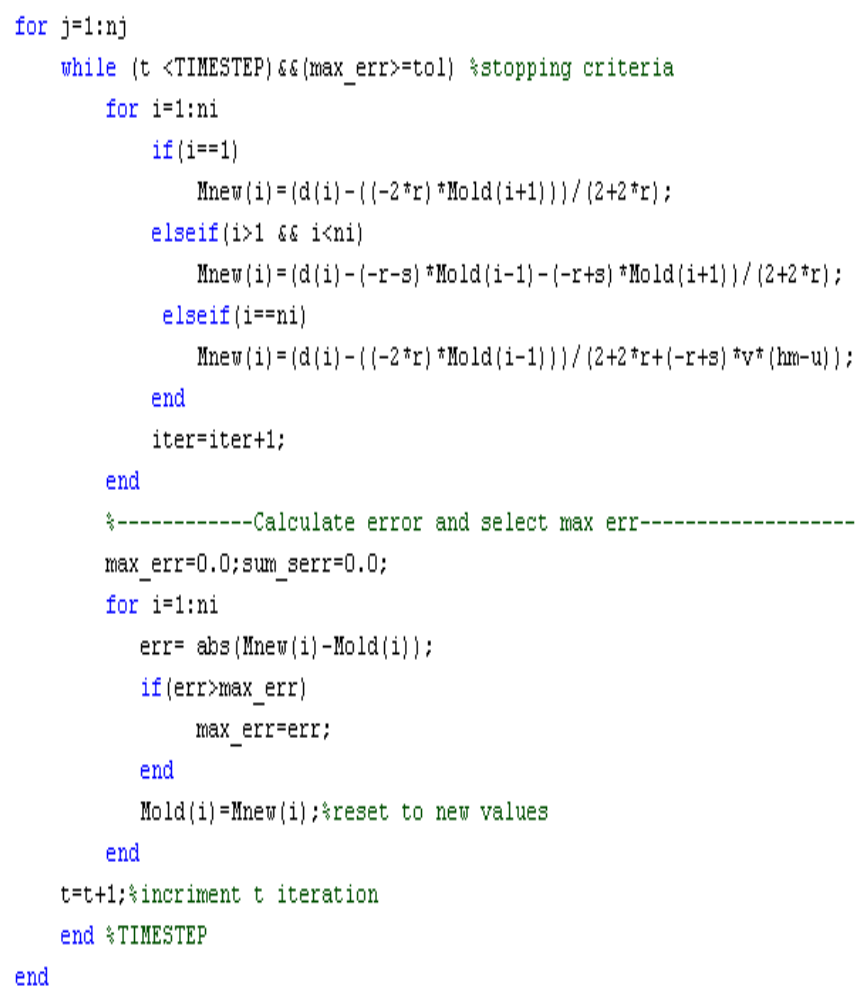

Figure 2: A part of MATLAB program

\section{NUMERICAL RESUlt AND DisCUSSION}

In this section, some numerical results are presented that illustrate the behavior of the method presented in section 3 . The platform for this computation is based on 
Intel ${ }^{\circledR}$ Core $^{\mathrm{TM}} 2 \mathrm{Quad}$ processors with windows XP operating system and MATLAB R2008a software. An analysis of the some iterative methods are cosidered. In order to evaluate the capabilities and performance of those iterative methods of the sequential algorithm, numerical results are demonstrated in Table 2 those were obtained from the simulation of the data configuration.

TABLE 2: DATA CONFIGURATION
\begin{tabular}{|ll|}
\hline $\mathrm{c}_{\mathrm{p}}$ & $1005.04(\mathrm{~J} / \mathrm{kg} \mathrm{K})$ \\
$\mathrm{D}$ & $6.61 \times 10-11$ \\
$h f g$ & $2358600(\mathrm{~J} / \mathrm{kg})$ \\
$\mathrm{k}$ & $0.0287(\mathrm{~W} / \mathrm{m} \mathrm{K})$ \\
$\mathrm{L}$ & $4 \mathrm{~mm}$ \\
$\mathrm{M}_{0}$ & $4 \mathrm{~kg} / \mathrm{kg}$ \\
$\mathrm{t}$ & $10800 \mathrm{~s}$ \\
$\mathrm{u}$ & $0.3(\mathrm{~m} / \mathrm{s})$ \\
\hline
\end{tabular}

\section{A. Geometric Visualization Of The Model Dehydration}

The COMSOL Multiphysic software was used to visualise the $3 \mathrm{D}$ geometry of the heat and moisture transfer equation in solving the dehydration problem as shown in Figure 3 and Figure 4.

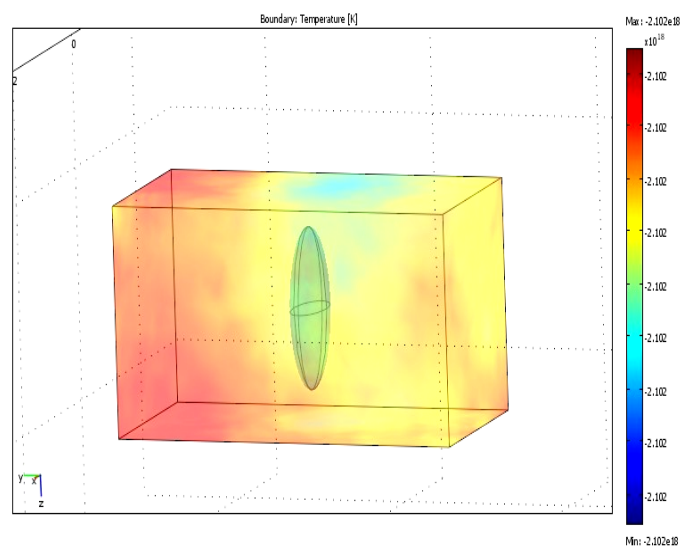

Figure 3: 3D Temperature visualization on the tropical herbs $(\mathrm{t}=10800 \mathrm{~s})$

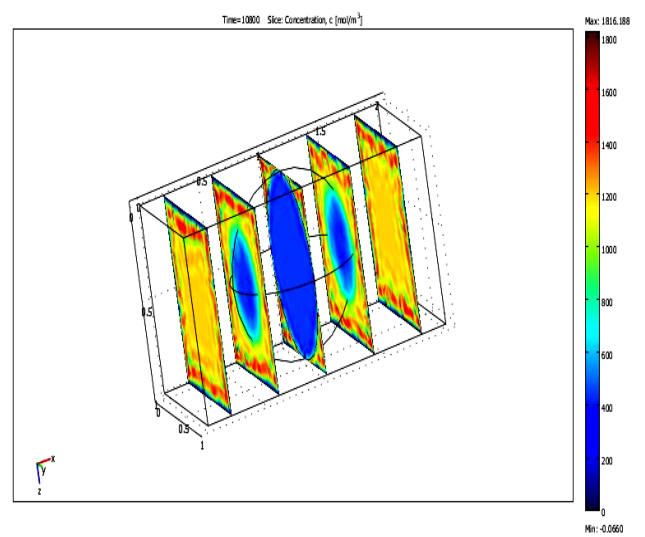

Figure 4: 3D Moisture visualization on the tropical herbs $(t=10800 s)$ Simulation of the dehydration

The graphical numerical results of moisture content and temperature using JB,GS and RBGS are displayed below. Figure 5 shows the moisture distribution and Figure 6 shows the temperature distribution during dehydration. The both distributions were within the sample of tropical herbs material during drying at $40^{\circ} \mathrm{C}$ with air velocity $0.3 \mathrm{~m} / \mathrm{s}$.

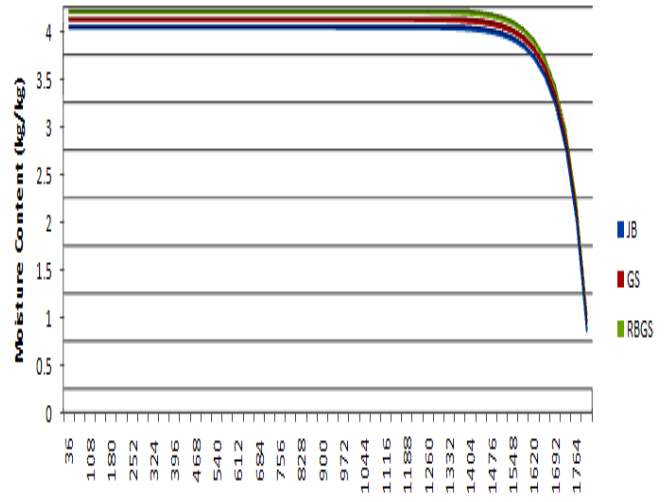

Figure 5: Evolution of Moisture content inside herbs material during dehydration with time; $\mathrm{T}=40^{\circ} \mathrm{c}, \mathrm{v}=0.3 \mathrm{~m} / \mathrm{s}$

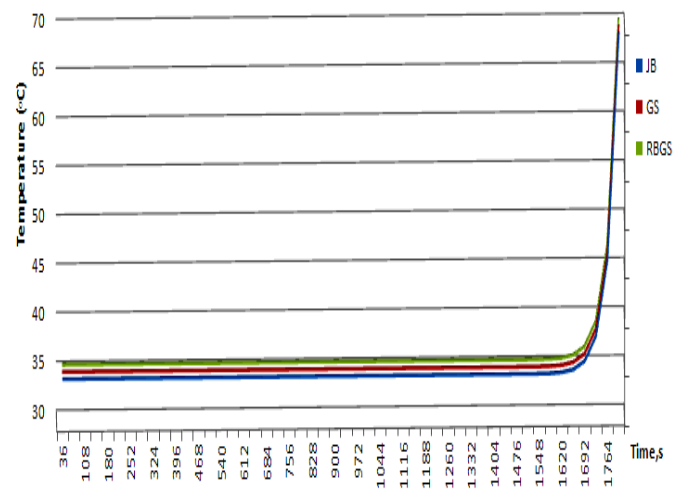

Figure 6: Evolution of temperature inside herbs material during dehydration with time; $\mathrm{T}=40^{\circ} \mathrm{c}, \mathrm{v}=0.3 \mathrm{~m} / \mathrm{s}$

From the both figures presented above, observed the parabolic curve of the moisture content and temperature behaviour. For all the solution methods under consideration, show the moisture content and temperature were looks like constant because their changes were very little and became large different changes after 1440 seconds for moisture and 1620 seconds for temperature. At the beginning of the dehydration process the evolution was practically constant and uniform until the last period it started different. Even the simulation results did not seem much different for all the iterative methods, the performance of every method was different. The numerical analysis in the next section will proof that.

\section{B. Performance evaluations}

In this section, the results of Numerical analysis involved the study of some iterative methods of computing numerical data in tropical herbs' dehydration. The analyses of performances involve the convergence and the accuracy of the numerical simulation data. Table 3 shows the convergence condition for every iterative method in terms of time execution, number of iteration, computational complexity and convergence rate. It also shows, the accuracy method was determined by computing Root Mean Square Error (RMSE) between the new and the previous iterations. The formula is given as the following,

$$
\operatorname{RMSE}=\sqrt{\sum_{i}^{N}\left(x_{j}^{(k+1)}-x_{j}^{(k)}\right)^{2} / N}
$$

The comparison was done for the $1.0 \mathrm{e}^{-5}$ tolerance rate and 
50 data size.

TABLE 3: NuMERICAL ANALYSIS FOR EACH METHOd IN MASS AND HEAT SIMULATION

\begin{tabular}{|c|c|c|c|c|c|c|c|}
\hline \multicolumn{2}{|c|}{$\begin{array}{c}\text { Numerical } \\
\text { Analysis }\end{array}$} & \multicolumn{3}{|c|}{ Mass Simulation } & \multicolumn{3}{|c|}{ Heat Simulation } \\
\hline & $\begin{array}{l}50, \\
\text { ance } \\
e-5\end{array}$ & $\begin{array}{c}\text { Jacob } \\
\quad \mathrm{i}\end{array}$ & $\begin{array}{c}\text { Gaus } \\
\text { s } \\
\text { Seide } \\
1\end{array}$ & $\begin{array}{c}\text { Red } \\
\text { Black } \\
\text { Gaus } \\
\text { s } \\
\text { Seide } \\
1\end{array}$ & $\begin{array}{c}\text { Jacob } \\
\mathrm{i}\end{array}$ & $\begin{array}{c}\text { Gaus } \\
\text { s } \\
\text { Seide } \\
1\end{array}$ & $\begin{array}{c}\text { Red } \\
\text { Black } \\
\text { Gaus } \\
\text { s } \\
\text { Seide } \\
1\end{array}$ \\
\hline \multicolumn{2}{|c|}{$\begin{array}{c}\text { Time } \\
\text { Execution(s) }\end{array}$} & $\begin{array}{c}0.001 \\
223\end{array}$ & $\begin{array}{c}0.000 \\
975\end{array}$ & $\begin{array}{c}0.000 \\
882\end{array}$ & $\begin{array}{c}0.000 \\
395\end{array}$ & $\begin{array}{c}0.000 \\
079\end{array}$ & $\begin{array}{c}0.000 \\
082\end{array}$ \\
\hline \multicolumn{2}{|c|}{ Iteration } & 99 & 60 & 55 & 31 & 18 & 16 \\
\hline \multicolumn{2}{|c|}{$\begin{array}{c}\text { Convergence } \\
\text { Rate }\end{array}$} & 1 & 0.61 & 0.56 & 1 & 0.58 & 0.52 \\
\hline \multirow{2}{*}{$\begin{array}{c}\text { com } \\
\text { puta } \\
\text { tion } \\
\text { al } \\
\text { com } \\
\text { plex } \\
\text { ity }\end{array}$} & $\begin{array}{c}\text { multi } \\
\text { plicat } \\
\text { ion }\end{array}$ & $\begin{array}{c}1664 \\
00\end{array}$ & $\begin{array}{c}1078 \\
48\end{array}$ & $\begin{array}{c}4950 \\
4\end{array}$ & $\begin{array}{c}5120 \\
0\end{array}$ & $\begin{array}{c}3040 \\
0\end{array}$ & $\begin{array}{c}1360 \\
0\end{array}$ \\
\hline & $\begin{array}{c}\text { additi } \\
\text { onal }\end{array}$ & $\begin{array}{c}1456 \\
00\end{array}$ & $\begin{array}{c}7295 \\
6\end{array}$ & $\begin{array}{c}3348 \\
8\end{array}$ & $\begin{array}{c}4480 \\
0\end{array}$ & $\begin{array}{c}2660 \\
0\end{array}$ & $\begin{array}{c}1190 \\
0\end{array}$ \\
\hline \multicolumn{2}{|c|}{$\begin{array}{l}\text { Absolute } \\
\text { Error }\end{array}$} & $\begin{array}{l}1.549 \\
45 \mathrm{e}-5 \\
\end{array}$ & $\begin{array}{l}9.866 \\
32 \mathrm{e}-6 \\
\end{array}$ & $\begin{array}{l}9.376 \\
58 \mathrm{e}-6 \\
\end{array}$ & $\begin{array}{l}7.049 \\
24 \mathrm{e}-6 \\
\end{array}$ & $\begin{array}{l}8.676 \\
32 \mathrm{e}-6 \\
\end{array}$ & $\begin{array}{l}8.116 \\
04 \mathrm{e}-6 \\
\end{array}$ \\
\hline \multicolumn{2}{|c|}{ RMSE } & $\begin{array}{l}1.353 \\
86 e-5\end{array}$ & $\begin{array}{l}5.060 \\
07 \mathrm{e}-6\end{array}$ & $\begin{array}{l}7.675 \\
67 \mathrm{e}-6\end{array}$ & $\begin{array}{l}2.422 \\
40 \mathrm{e}-6\end{array}$ & $\begin{array}{l}4.335 \\
89 \mathrm{e}-6\end{array}$ & $\begin{array}{l}1.833 \\
59 \mathrm{e}-6\end{array}$ \\
\hline
\end{tabular}

\section{Convergence Comparison}

Convergence comparison among Jacobi, Gauss-Seidel and Red Black Gauss-Seidel iterative methods are made in terms of the execution time and the number of iterations that it takes to converge.

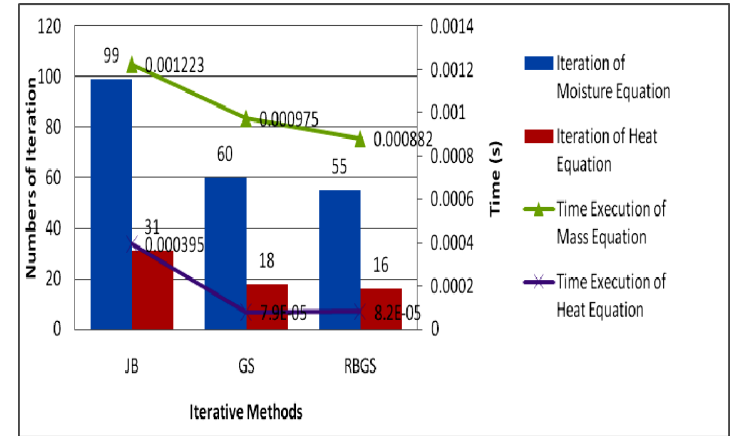

Figure 7: Convergence analysis among the numerical methods for mass and heat simulation

In Figure 7, the convergence in terms of execution time and number of iterations shows that either in mass or heat simulation, RBGS method performs faster than JB and GS methods. RBGS provides the lowest number of iterations and the shortest time of execution to converge followed by JB method and GS method.

The execution time depends on the number of iterations and computational complexity. Figure 7 shows that JB takes highest execution time compared to GS and RBGS in both simulations. During the simulation of moisture content through dehydration, JB needs 44 iterations more than RBGS to converge. While GS only needs more 5 iterations compared to RBGS. In contrast during temperature simulation, although RBGS gives the lowest iteration to converge, but the differences between RBGS, GS and JB are not so much than mass simulation.

Computational complexity refers to the number of arithmetic operations involved in numerical simulation. The computational complexity of each iterative method is increasing by the number of iterations. Table 3 shows, JB produced the highest number of operations in multiplication and addition. It is followed by GS and RBGS. The results also show that RBGS method has the fastest rate of convergence among other methods, those took under consideration in this study. RBGS has $0.48 \%$ faster than JB and only $0.06 \%$ faster than GS in terms of convergence rate. The results above proved that RBGS method is the alternative iterative method with the lowest computational complexity as well as the minimum time of execution, number of iterations and convergence rate.

\section{Accuracy performance}

The accuracy method was determined by computing root mean square error. The lowest value of root mean square error indicates the most accurate method. Absolute error also can describe the accuracy of each method. From the table 3, it is shown that RBGS provides smallest value of RMSE as well as absolute error.

\section{CONCLUSION AND DISCUSSION}

A mathematical simulation model using the one dimensional parabolic equation regarding the moisture and temperature behavior of tropical herbs during dehydration has been presented. Three iterative methods such as Jacobi, Gauss-Seidel and Red Black Gauss-Seidel are studied. According to the Table 3 and Figure 7, it is proved that the RBGS method is the best method to solve heat and mass transfer equation numerically followed by Gauss Seidel and Jacobi method. The results of numerical analysis such as time execution, number of iteration, computational complexity, root mean square error and rate of convergence has proved that this dehydration model is capable to simulate mass and temperature distribution through numerical method approach. Concerning the evolution of integration technologies in the production of herbs based products especially tropical herbs, it is necessary to simulate more often in order to avoid high costs and to get better process condition and parameters with the desirable accuracy. The contribution of this study is to successfully modify the mathematical simulation in representing the genuine process of dehydration at the herbs industry. It is also time consuming and capable to reduce the risk of real experiments in the actual process. The future contribution of this study can be the use of parallel algorithm to solve the model of dehydration. Parallel algorithm will improve numerical computation particularly while dehydration involves with huge data size. The computational time and complexity increase during huge data size simulation/calculation. Hence, parallel computation becomes an obligation.

\section{ACKNOWLEDGMENT}

The authors acknowledge the Ibnu Sina Institute, University Technology Malaysia and Ministry of Science, Technology and Innovation (MOSTI), Malaysia for the financial support under Research Grant 78363. 


\section{REFERENCES}

[1] Ahmet Kaya, Orhan Aydin and Ibrahim Dincer, "Numerical modeling of heat and mass transfer during forced convection drying of rectangular moist objects," International Journal of heat and mass transfer, vol. 49(17-18), 2006, pp. 3094-3103.

[2] Ahmet Kaya, Orhan Aydin and Ibrahim Dincer, "Experimental and numerical investigation of heat and mass transfer during drying of hayward kiwi fruits (Actinidia Deliciosa Planch)," Journal of Food Engineering, vol. 88(3), 2008, pp. 323-330.

[3] Amendola, M. and Queiroz, M.R., "Mathematical methodologies for calculating the mass diffusion coefficient of bananas during drying," Revista Brasileira de Engenharia Agricola e Ambiental, vol. 11(6), 2007, pp. 623-627.

[4] Giampaolo Betta, Massimiliano Rinaldi, Davide Barbanti and Roberto Massni, "A quick method for thermal diffusivity estimation: Application to several foods," Journal of food Engineering, vol. 91(1), 2009, pp. 34-41.

[5] Curcio, S., "A FEM analysis of transport phenomena occuring during vegetables drying," Proceeding of the COMSOL Conference 2009 Milano, 2009.

[6] Gavrila, C., "Heat and mass transfer in convective drying processes.," Proceedings of the COMSOL Conference 2008 Hannover, 2008.

[7] Md Azharul Karim \& Hawlader, M.N.A, "Drying characteristic of banana: theoritical modelling and experimental validation," Journal of Food Enggineering, vol. 70, 2005, pp. 35-45.

[8] Md Azharul Karim \& Hawlader, M.N.A, "Mathematical modelling and experimental investigation of tropical fruits drying," International Journal of Heat and Mass Transfer, vol. 48, 2005, pp. 4914-4925.

[9] Maroulis Z. B., Kiranoudis C. T., and Marinos-Kouris D.. "Heat and mass transfer modeling in air drying of foods," Journal of food engineering, vol. 26 (1), 1995, pp. 113-130.

[10] Mujumdar, A.S., "Some recent developments in drying technologies appropriate for postharvest processing," International Journal of Postharvest Technology and Innovation, 2006.

[11] Queiroz, M.R. and Nebra, S.A., "Theoretical and experimental analysis of the drying kinetics of bananas," Journal of food Engineering, vol. 47, 2001, pp. 127-132.

[12] Tabrizi, H.B. and Hamdullahpur, F., "Mathematical modeling of drying bed on a surface evaporation source term for coupled energy and mass transfer," International Journal of Energy Research, vol. 31, 2007, pp. $1455-1464$.

[13] Wang, N. and Brennan, J.G. "A mathematical model of simultaneous heat and moisture transfer during drying of potato," Journal of Food Engineering, vol. 24, 1995, pp. 47-60.

[14] Norma Alias, Md. Rajibul Islam and Nur Syazana Rosly, "A dynamic PDE solver for breasts' cancerous cell visualization on distributed parallel computing systems", in Proc. of The 8th International Conference on Advances in Computer Science and Engineering (ACSE 2009), Phuket, Thailand, 2009, pp. 138-143.

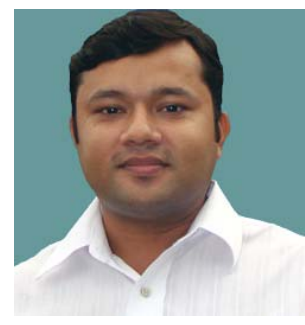

Md. Rajibul Islam received his Bachelor of Computer Applications (BCA) degree from the Indira Gandhi National Open University, New Delhi, India, in 2004 and M.Sc in Information Technology degree from Multimedia University, Melaka, Malaysia Currently he is working as a Research Assistant at Ibnu Sina Institute, in Science Faculty of University Technology Malaysia, Johor. His research interests include Distributed Parallel Computing, Numerical Computation, Pattern Recognition, Image Processing, Computer Vision, and Artificial Intelligence.

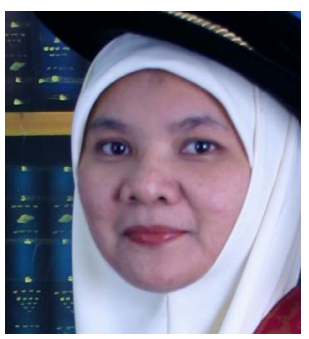

Dr. Norma Alias obtained her $\mathrm{PhD}$ (Industrial Computing: Parallel Computing) from National University of Malaysia in 2004 and her M.Sc degree in Industrial Computing and BSc in Mathematics from the same University in 1997 and 1991 respectively. Currently, she is a Senior lecturer at the Mathematics Department in Faculty of Science, University Technology Malaysia (UTM) and the Researcher Head of High Performance Computing Group as well in Ibnu Sina Institute, UTM. She has published over 100 papers in several referred International journals, conferences, workshops, lecture notes and book chapters. She is a reviewer of several International Journals with high impact factor and association with some International conferences and workshops organized by Ibnu Sina Institute. Her research interests include Industrial Computing, Numerical Computation, and Scientific Computing \& High Performance Computing on Distributed Parallel Computer Systems. 